\title{
“One Ring to Bind Them All”-_Part II: Identification of Promising G-Quadruplex Ligands by Screening of Cyclophane-Type Macrocycles
}

\author{
Anton Granzhan, ${ }^{1}$ David Monchaud, ${ }^{1,2}$ Nicolas Saettel, ${ }^{1}$ Aurore Guédin, ${ }^{3}$ \\ Jean-Louis Mergny, ${ }^{4}$ and Marie-Paule Teulade-Fichou ${ }^{1}$ \\ ${ }^{1}$ Section Recherche, Institut Curie, CNRS UMR176, Centre Universitaire Paris XI, Bat. 110, 91405 Orsay, France \\ ${ }^{2}$ Institut de Chimie Moléculaire, CNRS UMR5260, Université de Bourgogne, 21000 Dijon, France \\ ${ }^{3}$ INSERM, U565, Acides Nucléiques: Dynamique, Ciblage et Fonctions Biologiques es CNRS, UMR5153, Laboratoire des \\ Régulations et Dynamique du Génome, Muséum National d’histoire Naturelle USM 503, 43, Rue Cuvier, 75005 Paris, France \\ ${ }^{4}$ INSERM U869, Institut Européen de Chimie et Biologie, Université de Bordeaux, 33607 Pessac cedex, France \\ Correspondence should be addressed to Marie-Paule Teulade-Fichou, mp.teulade-fichou@curie.fr
}

Received 29 January 2010; Accepted 10 February 2010

Academic Editor: R. Eritja

Copyright ( $\odot 2010$ Anton Granzhan et al. This is an open access article distributed under the Creative Commons Attribution License, which permits unrestricted use, distribution, and reproduction in any medium, provided the original work is properly cited.

A collection of 26 polyammonium cyclophane-type macrocycles with a large structural diversity has been screened for Gquadruplex recognition. A two-step selection procedure based on the FRET-melting assay was carried out enabling identification of macrocycles of high affinity $\left(\Delta T_{1 / 2}\right.$ up to $\left.30^{\circ} \mathrm{C}\right)$ and high selectivity for the human telomeric G-quadruplex. The four selected hits possess sophisticated architectures, more particularly the presence of a pendant side-arm as well as the existence of a particular topological arrangement appear to be strong determinants of quadruplex binding. These compounds are thus likely to create multiple contacts with the target that may be at the origin of their high selectivity, thereby suggesting that this class of macrocycles offers unique advantages for targeting G-quadruplex-DNA.

\section{Introduction}

The macrocyclic scaffold has proven to be highly valuable for the design of efficient and selective G-quadruplex ligands (see the review article in the present issue, "One Ring to Bind Them All"-Part I, by Monchaud et al.) [1-4]. Along these lines, two families of macrocyclic ligands have been particularly and thoroughly studied for their ability to specifically interact with quadruplex-DNA, namely, the families of telomestatin- [5] and porphyrin (TMPyP4)-related compounds [6-8]. Recently, a third family has emerged, namely the polyammonium cyclophane-type macrocycles, generally referred to as "CBI macrocycles" (for Cyclo-BisIntercalators), that adopt a non-planar conformation and therefore are structurally highly different from the two aforementioned classes. The efficiency of this family of ligands with regard to quadruplex DNA recognition is particularly illustrated by the compound $\mathrm{BOQ}_{1}$ (Figure 1(a)) [9-11] as discussed in "One Ring to Bind Them All"-Part I. This compound is comprised of two large aromatic quinacridine units [12-14] able to interact with DNA bases through $\pi$ $\pi$ interactions, and linked together via two short polyamine side chains, which ensure a global tetracationic charge at physiological $\mathrm{pH}$ affording both high water solubility and strong electrostatic attraction to DNA.

We have previously reported that $\mathrm{BOQ}_{1}$ exhibits a high affinity for the human telomeric G-quadruplex DNA, along with a poor ability to associate with double-stranded DNA [9-11]. Consequently, this compound not only rivals the performances of telomestatin and TMPyP4 in terms of quadruplex-affinity (Figure 1(c)) [16], but elicits a quadruplex- over duplex-DNA selectivity comparable to that of telomestatin and highly superior to that of TMPyP4. One key to explain the very good quadruplex-binding properties 


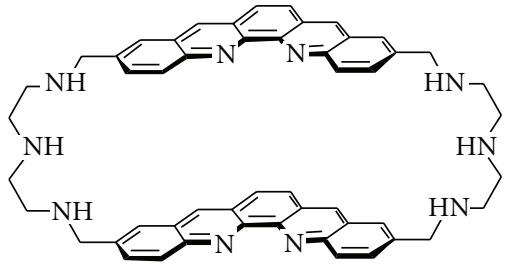

(a)

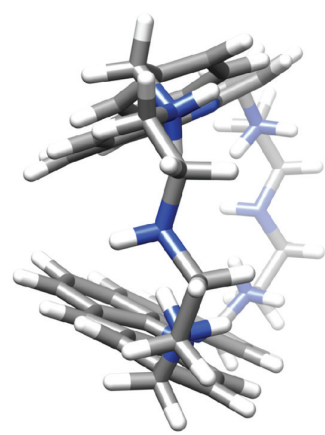

(b)

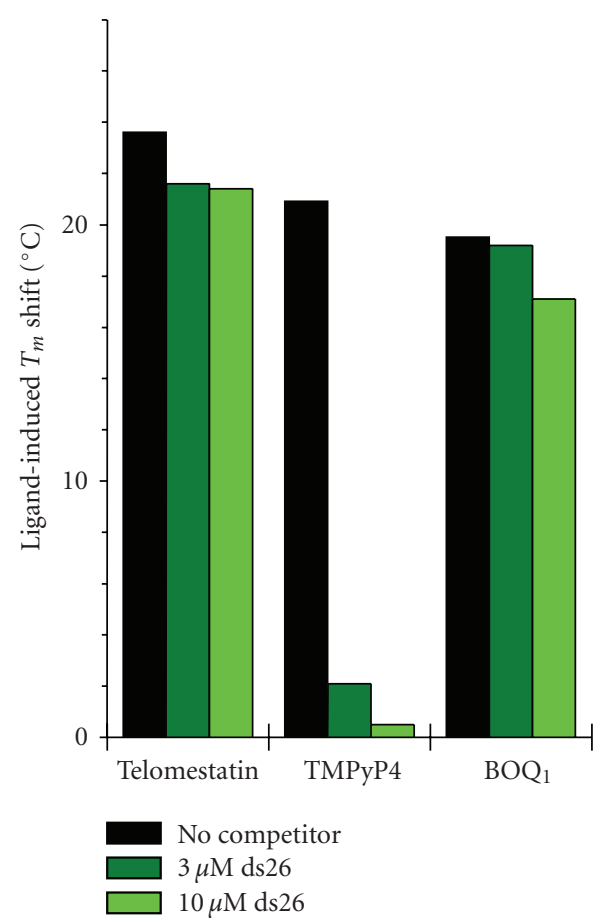

(c)

FIGURE 1: (a) Structure of $\mathrm{BOQ}_{1}$. (b) Side-view of the lowest-energy conformation of $\mathrm{BOQ}_{1}$ during the molecular dynamic simulation. (c) FRET-melting results obtained with telomestatin, TMPyP4, and $\mathrm{BOQ}_{1}(1 \mu \mathrm{M})$, for experiments carried out with $0.2 \mu \mathrm{M}$ F21T in lithium cacodylate buffer $(10 \mathrm{mM}, \mathrm{pH} 7.2)$ with $\mathrm{NaCl}(100 \mathrm{mM})$, in the absence (black bars) or in the presence of 3 (dark green bars) or $10 \mu \mathrm{M}$ (light green bars) of double-stranded competitor (ds26). (It is worth noting that the FRET-melting values obtained herein for BOQ ${ }_{1}$ differ from that of the initial publication (see [9]). This discrepancy originates in the different experimental conditions used, given that FRET-melting is performed herein as an HTS unlike the initial report (single-cell experiment); the disparities between the two methods are extensively detailed in [15] (among which can be cited the final volume (25 versus $600 \mu \mathrm{L})$, the buffer conditions $(10 \mathrm{mM}$ lithium cacodylate $+100 \mathrm{mM}$ $\mathrm{NaCl}$ versus $10 \mathrm{mM}$ sodium cacodylate, $100 \mathrm{mM} \mathrm{LiCl}$ ), etc.).)

of CBIs stands in their peculiar structural organization, which represents a non-planar conformation with a significant degree of molecular flexibility [11], thus clearly distinct from the planar rigid macrocycles telomestatin and TMPyP4. Indeed, previous works (NMR, X-rays and molecular modelling studies, vide infra) have shown that the CBI scaffold exists in a semiclosed conformation (Figure 1(b)) that results both from internal hydrophobic interactions between the two aromatic moieties and from a constrained distance between them imposed by the linkers [17]. This particular spatial organization is an essential determinant that governs the interaction of CBIs with secondary structures of DNA. In the case of quadruplex-DNA, BOQ ${ }_{1}$ was initially thought to interact in an open-state conformation [9], but subsequent modelling studies [11] as well as recent molecular dynamics studies [18], suggested that the CBI scaffold never adopts the fully open conformation. In fact the semi-closed conformation of $\mathrm{BOQ}_{1}$ has been shown to be not only the most stable conformation after in silico geometry optimization (Figure 1(b)) but also to be the favoured one when interacting with quadruplex structures (see "One Ring to bind them all"-Part I) [11]. It is thus hypothesized that this particular structure is at the origin of the efficient G-quadruplex recognition performed by $\mathrm{BOQ}_{1}$, which is supposed to occur via a mixed binding mode combining quartet and loop interactions. Finally, given that the length of the polyammonium linker does not enable intercalation of both aromatic residues between contiguous base pairs in duplex-DNA due to the neighbour-exclusion principle $[19,20]$, the macrocyclic scaffold of $\mathrm{BOQ}_{1}$ impedes binding to duplex-DNA, and consequently is responsible for the good selectivity for quadruplex- versus duplex-DNA.

The promising results obtained with $\mathrm{BOQ}_{1}$ in terms of quadruplex recognition and selectivity prompted us to screen a collection of 26 CBI-type macrocycles previously synthesized $[17,18,21,22]$. The members of this series (represented schematically in Figure 2, in extenso in Figure 3 ) differ by the nature of the aromatic units, the topology of the macrocyclic framework that contains either two different aromatic units or the same units, but with different connectivities; the nature and the derivatization of the linking chains; and finally the number of the constitutive "intercalator" units (two for CBI, three for CTI (Cyclo-Tris-Intercalators), Figure 2). In detail, the macrocycles are comprised of either polyaromatic cycles (naphthalene, anthracene, and biphenyl moieties), or heterocycles (such as acridine, quinacridine, phenanthroline, phenazine and bipyridine moieties) or even an organometallic unit (ferrocene), along with the possibility 


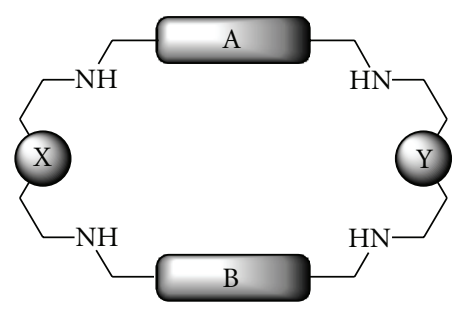

(a)

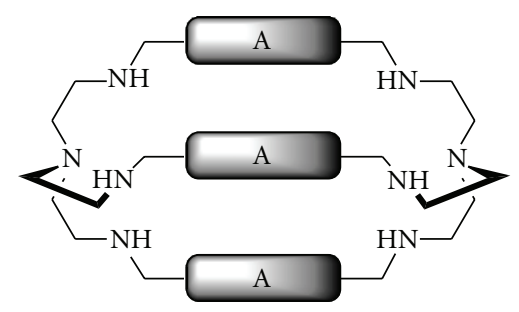

(b)

FIGURE 2: General representation of CBI (a) and CTI (b) macrocycles studied in this work. A, B: (hetero)aromatic residues; X, Y: O, NH, S, or pendant side arms.

of various connectivities that can be present in a given series. Moreover, oxygen or sulphur atoms were introduced in the linking chains in place of the secondary amino groups present in $\mathrm{BOQ}_{1}(\mathrm{X}=\mathrm{Y}=\mathrm{NH}, \mathrm{O}$ or $\mathrm{S}$, Figure 2$)$, and in some cases the linkers bear tertiary amino groups due to substitution with pendant $\operatorname{arms}(\mathrm{X}=\mathrm{Y}=\mathrm{NR})$. All these structural variations allow to divide the present collection of macrocycles into four categories (Figure 3): (a) homodimeric macrocycles, containing two identical aromatic units $(\mathrm{A}=\mathrm{B})$; $(\mathrm{b})$ heterodimeric macrocycles, containing two different aromatic units $(\mathrm{A} \neq \mathrm{B})$; $(\mathrm{c})$ pendant-arm macrocycles containing a bisnaphthalene scaffold ( $\mathrm{A}=\mathrm{B}=2,6$-naphthylene) with one (monobrachial) or two (bibrachial) side-chains with additional functional groups; and (d) homotrimeric macrocycles (cryptand-type) containing three identical aromatic units. With this series in hand, we systematically studied the influence of the various structural components of the macrocyclic scaffold on both the quadruplex-affinity and selectivity.

\section{Results and Discussion}

To evaluate the 26 compounds shown in Figure 3, we used the FRET-melting assay, which has been recently developed to a high-throughput screening format and provides reliable information concerning quadruplex-affinity and -selectivity in a straightforward manner [15]. This method is based on monitoring the ligand-induced stabilization of a fluorescently labelled quadruplex-forming structure (F21T, FAM- $\mathrm{G}_{3}\left[\mathrm{~T}_{2} \mathrm{AG}_{3} \mathrm{~T}\right]_{3}-$ Tamra). The stabilization, measured via a fluorescence resonance energy transfer (FRET) between the two fluorescent partners (6-carboxyfluorescein, FAM, and 6-carboxytetramehtylrhodamine, Tamra), is expressed as an increase in melting temperature of F21T $\left(\Delta T_{1 / 2}\right)$ in the presence of the ligand. This method also enables to gain insight into the quadruplex- over duplexDNA selectivity if the melting experiments are carried out in the presence of various amounts of a 26-bp doublestranded DNA competitor (ds26, the self-complementary $\left[5^{\prime}-\mathrm{CA}_{2} \mathrm{TCG}_{2} \mathrm{ATCGA}_{2} \mathrm{~T}_{2} \mathrm{CGATC}_{2} \mathrm{GAT}_{2} \mathrm{G}-3^{\prime}\right]$, up to 50 equiv.) Last but not least, FRET-melting enables also a direct comparison with recently reported ligands, given that this technique is now widely used by the quadruplex DNA community and often, as it is the case herein, as a test for the primary selection of ligands.

\section{Selection of the High-Affinity Ligands}

In the first round of experiments, we searched for the ligands with high affinity for the human telomeric quadruplexDNA. FRET-melting experiments were thus carried out in the standard conditions previously calibrated for selection of high-affinity ligands [15], that is, with $0.2 \mu \mathrm{M}$ F21T and $1 \mu \mathrm{M}$ ligand. This first round of selection was performed both in sodium $(10 \mathrm{mM}$ lithium cacodylate, $100 \mathrm{mM} \mathrm{NaCl})$ and potassium conditions $(10 \mathrm{mM}$ lithium cacodylate, $10 \mathrm{mM}$ $\mathrm{KCl}, 90 \mathrm{mM} \mathrm{LiCl}$ ) of identical ionic strength. This systematic comparison was necessary since the telomeric quadruplex is known to fold into different conformations depending on the cation present in the medium, displaying different loop arrangements that might result in differences in ligand binding [23-25]. The two conformations currently admitted to correspond to the predominant species in solution and in each are represented in Figure 1 of "One Ring to Bind Them All"-Part I. The results of the FRET-melting experiments with the 26 macrocycles are presented as a bar graph in Figure 4.

This series of experiment enabled us to classify the compounds in two categories, namely the high-affinity ligands $\left(\Delta T_{1 / 2}>10^{\circ} \mathrm{C}\right)$ and the ligands of moderate to low affinity $\left(\Delta T_{1 / 2}<10^{\circ} \mathrm{C}\right)$. The selection criteria, that is, the affinity threshold of $10^{\circ} \mathrm{C}$, was motivated by the experience acquired over the past years when developing the FRETmelting assay.

As depicted in Figure 4, ten compounds (corresponding to blue structures in Figure 3 ) did not reach the affinity threshold (2,7-BisNP-S, 1,5-BisNP, 9,10-BisAN, 1,8BisAN, 1,8/9,10-BisAN, 4,4'-BisBPy, 2,8-BisPZ, 4,7-BisPN, 2,7-NP/1,1'-FC, and 2,8-TrisPZ). Among the ligands which induce a stabilization by over $10^{\circ} \mathrm{C}, 8$ ligands (corresponding to black structures in Figure 3) display a high quadruplexaffinity $\left(10^{\circ} \mathrm{C}<\Delta T_{1 / 2}<20^{\circ} \mathrm{C}: 2,7-B i s N P, 2,7-B i s N P-N\right.$, 1,5/2,6-BisNP, 3,3'-BisBP, 4,5-BisA, 2,7-NP/9,10-AN, 2,7$\mathrm{NP} / 2,7-\mathrm{A}$ and $3,3^{\prime}$-TrisBP), and 8 ligands (corresponding to red structures in Figure 3 ) elicit a very high affinity $\left(\Delta T_{1 / 2}>20^{\circ} \mathrm{C}: 2,6\right.$-BisNP, 2,9-BisPN, BisNP-1NH2, BisNP1PY, BisNP-2PY, BisNP-1FC, BisNP-2FC, and 2,7-TrisNP). It is worth noting that a $\Delta T_{1 / 2}$ value of $30-35^{\circ} \mathrm{C}$ as observed for BisNP-2PY represents the upper practical limit of the assay (corresponding to a $T_{\mathrm{m}} \geq 80-85^{\circ} \mathrm{C}$ for the ligand-DNA complex). 


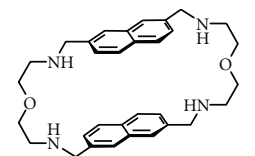

2,7-BisNP
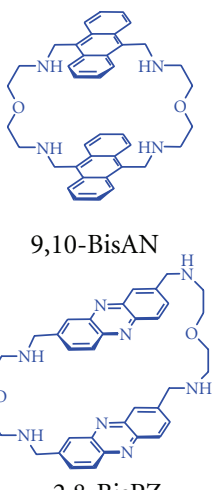

2,8-BisPZ

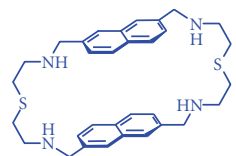

2,7-BisNP-S

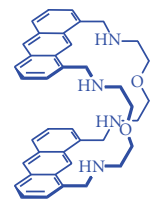

1,8-BisAN

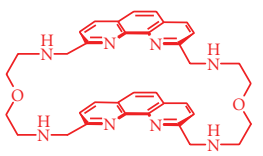

2,9-BisPN

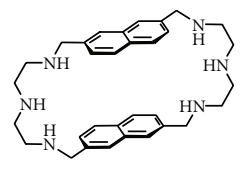

2,7-BisNP-N

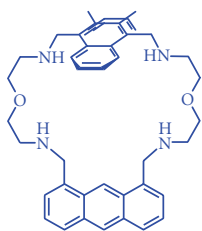

1,8/9,10-BisAN

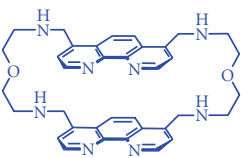

4,7-BisPN
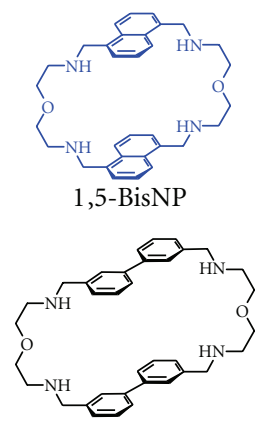

3, $3^{\prime}-$ BisBP
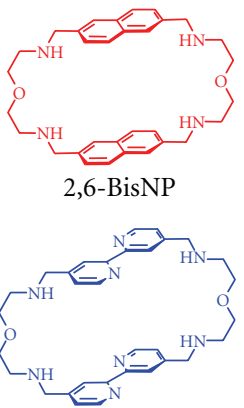

4, $4^{\prime}$-BisBPy
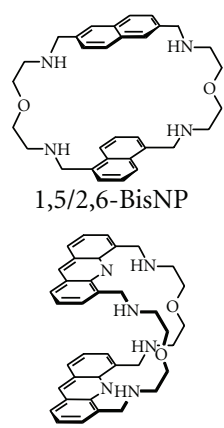

4,5-BisA

(a) Homodimeric macrocycles

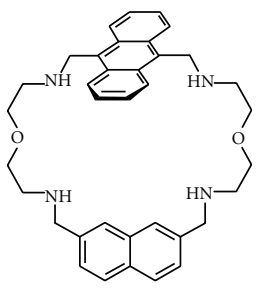

2,7-NP/9,10-AN

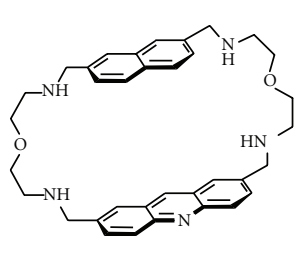

2,7-NP/2,7-A

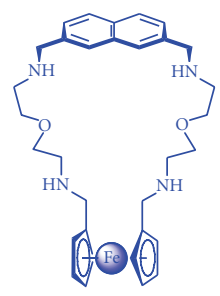

2,7-NP/1,1'-FC

(b) Heterodimeric macrocycles

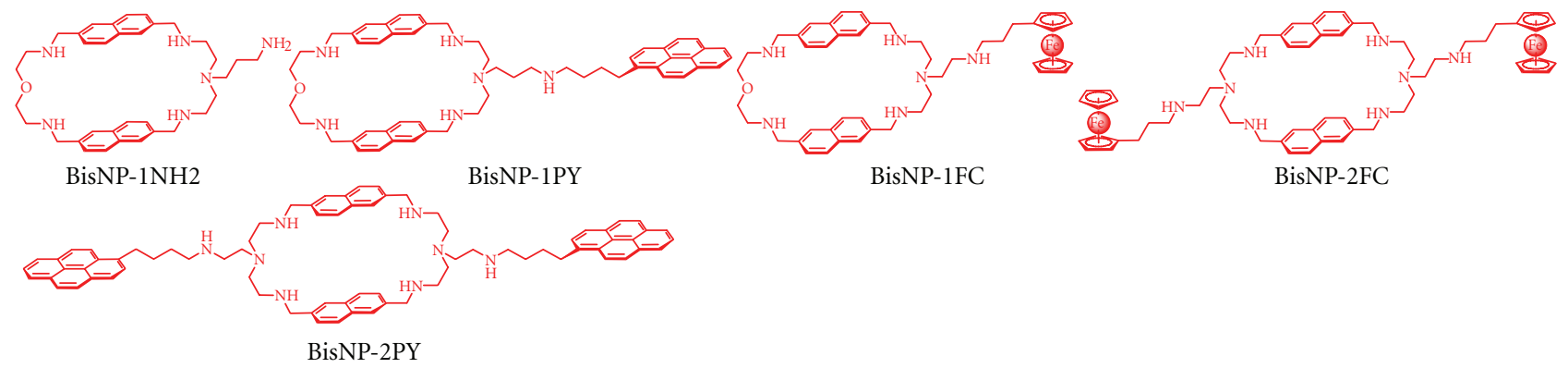

(c) Homodimeric pendant-arm macrocycles

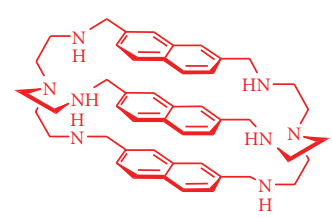

2,7-TrisNP

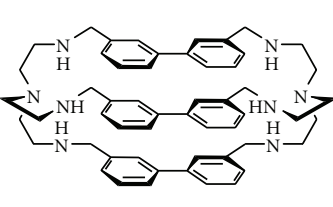

3,3'-TrisBP

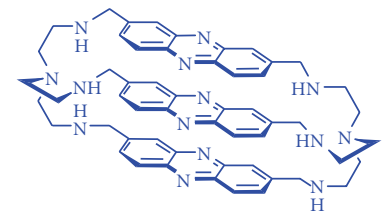

2,8-TrisPZ

(d) Homotrimeric macrocycles

Figure 3: Structures of the 26 studied CBIs; see text below for the explanations of the color codes related to affinity and selectivity of the ligands. 


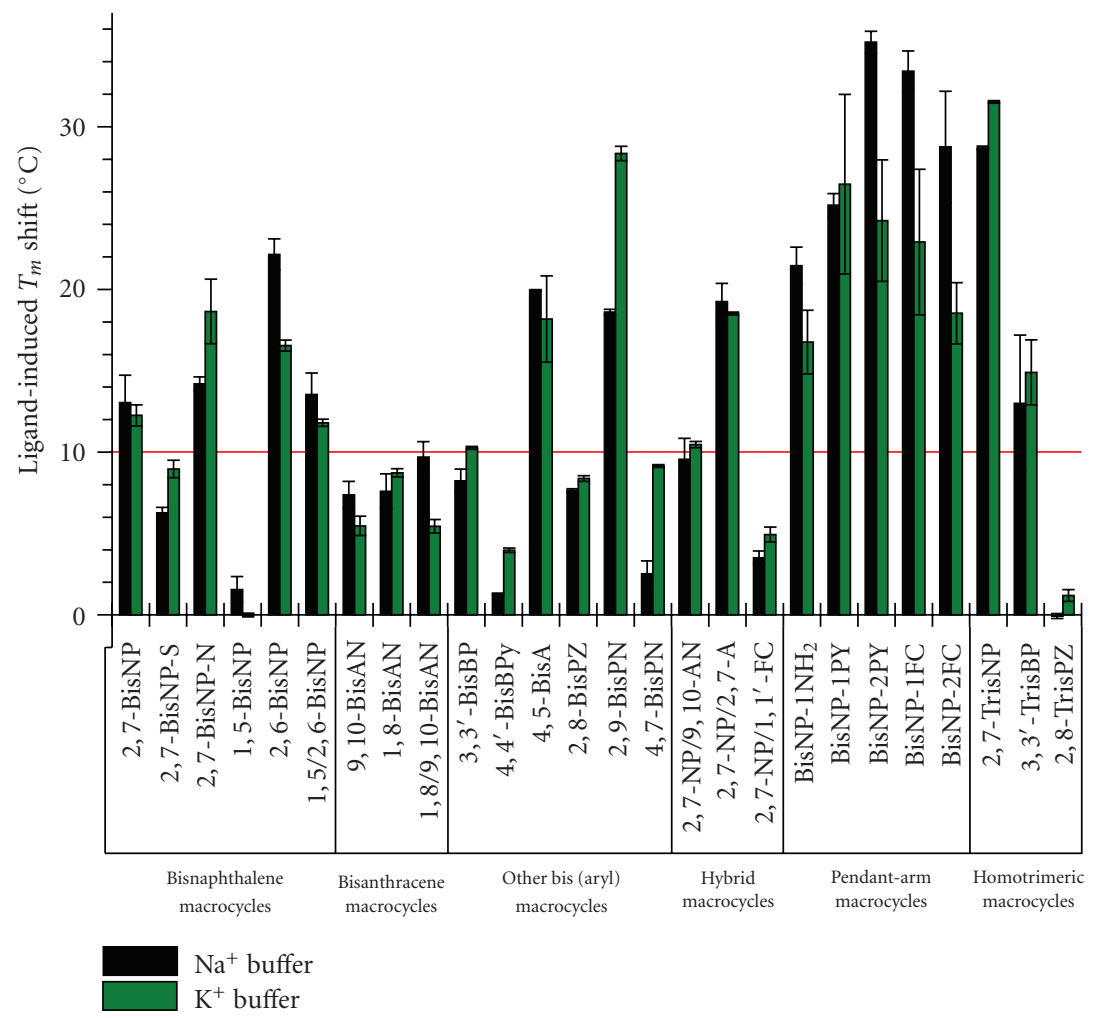

FIgURE 4: Stabilisation of F21T oligonucleotide $\left(\Delta T_{1 / 2},{ }^{\circ} \mathrm{C}\right)$ induced by CBI macrocycles $(1 \mu \mathrm{M})$ in $\mathrm{Na}^{+}$- (black bars) or $\mathrm{K}^{+}$-rich conditions (green bars); see main text for experimental details.

A close examination of these results enables us to identify the parameters that influence the efficiency of the quadruplex-recognition by the macrocyclic scaffold, namely, (a) the nature and (b) the connectivity of the intercalator units, (c) the nature of the linker, (d) the global charge of the ligand and (e) the number of intercalator units.

(a) The nature of the intercalator unit: (i) rigid fused aromatic units lead to better results than the unfused flexible ones. Indeed, the two CBIs containing biphenyl or bipyridine units $3,3^{\prime}$-BisBP and $4,4^{\prime}$ BisBPy induce a lower stabilization $\left(\Delta T_{1 / 2} \mathrm{Na} / \mathrm{K}=\right.$ $8.2 / 10.4$ and $1.3 / 4.0^{\circ} \mathrm{C}$, resp.) than the corresponding naphthalene analogue 2,7-BisNP $\left(\Delta T_{1 / 2} \mathrm{Na} / \mathrm{K}\right.$ $=9.1 / 12.2^{\circ} \mathrm{C}$ ). (ii) The size of the aromatic units appears less important than their relative arrangement, since the four ligands comprising an anthracene unit (i.e., the largest intercalator used herein), namely, 1,8-, 9,10-, 1,8/9,10-BisAN and the anthracene-naphthalene hybrid 2,7-NP/9,10-AN, give results either below (the three former) or just reaching (the latter) the affinity threshold, whereas most naphthalene derivatives strongly stabilize the quadruplex-DNA. (iii)- Finally, the presence of two flat aromatic units in the typical CBI arrangement is an absolute requirement, as shown by the poor quadruplex-stabilizing properties of the unsymmetrical macrocycle $2,7-\mathrm{NP} / 1,1$ '-FC containing a bulky ferrocene unit $\left(\Delta T_{1 / 2}<5^{\circ} \mathrm{C}\right)$. (b) The connectivity of the intercalator units: the connectivity of the two aromatic units determines the conformation and the internal molecular dynamics of the macrocycle. Consequently, it must have a profound influence on the DNA binding ability. This is fully confirmed herein by the striking differences observed within a given series: for example, in the naphthalene series, the 1,5-BisNP does not induce notable stabilization $\left(\Delta T_{1 / 2}<2{ }^{\circ} \mathrm{C}\right)$ while 2,6 -BisNP and 2,7-BisNP are above the affinity threshold $\left(\Delta T_{1 / 2} \mathrm{Na} / \mathrm{K}=19.6 / 18.3\right.$ and $9.1 / 12.2^{\circ} \mathrm{C}$, resp. $)$. Similar conclusions can be drawn for the phenanthroline series, since 2,9-BisPN is much more efficient than its analogue $4,7-\operatorname{BisPN}\left(\Delta T_{1 / 2}=13.8 / 16.8\right.$ and $2.5 /$ $9.1^{\circ} \mathrm{C}$, resp.).

(c) The nature of the linker: interestingly, the replacement of the central oxygen atom by a sulfur atom $(2,7$ BisNP versus 2,7-BisNP-S) significantly reduces the stabilisation $\left(\Delta T_{1 / 2} \mathrm{Na} / \mathrm{K}=9.1 / 12.2\right.$ and $6.3 / 9.0^{\circ} \mathrm{C}$, resp.), an observation that can be attributed to the larger steric hindrance of the sulfur atom. On the other hand, the replacement of the central oxygen atom by a nitrogen atom improves the stabilization (2,7-BisNP versus 2,7-BisNP-N, $\Delta T_{1 / 2} \mathrm{Na} / \mathrm{K}=9.1 /$ 12.2 and $13.3 / 16.3^{\circ} \mathrm{C}$, resp.), suggesting a possible involvement of the $\mathrm{NH}$ group in $\mathrm{H}$-bond interactions with the quadruplex target. 


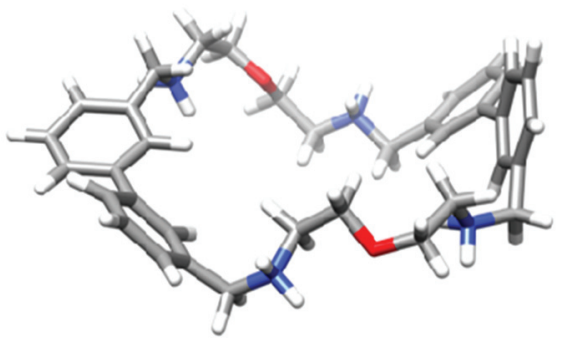

(a)
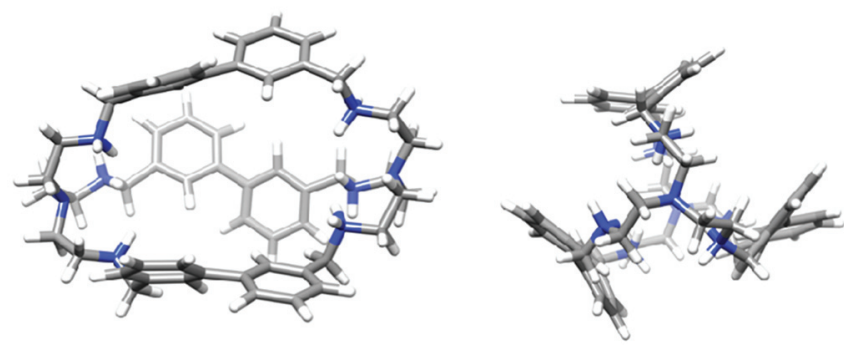

(b)

FIGURE 5: Lowest energy conformations of (a) 3, 3'-BisBP and (b) 3, 3' -TrisBP (front and side-view) during a molecular dynamic simulation in a water box [29].

(d) The global charge of the ligand: previous studies have shown that only the benzylic nitrogens of the linkers are protonated at the experimental $\mathrm{pH}$ (7.2) both in the CBI and CTI series [26-28]. Thus, it can be assumed that the global cationic charge of the whole series varies from 4 (for CBIs) to 5 (for monosubstituted CBIs) up to $6+$ (for disubstituted CBIs and CTIs). The data collected (Figure 4) show that there is no obvious dependence on the global charge of the ligand given that CBI compounds (4+) globally induce better stabilizations than CTI compounds $(6+)$ and that the monosubstituted CBIs (5+) are more efficient than their disubstituted analogues $(6+)$. We can conclude that the quadruplex-recognition is not dominated only by electrostatic parameters, although this interaction may contribute strongly to the stabilisation effect.

(e) The number of intercalative units: the number of intercalative units appears to play a crucial role since, in the biphenyl series, the bismacrocycle $3,3^{\prime}$-BisBP is less efficient than the corresponding trismacrocyclic compound $3,3^{\prime}$-TrisBP $\left(\Delta T_{1 / 2} \mathrm{Na} / \mathrm{K}=8.2 / 10.4^{\circ} \mathrm{C}\right.$ and $\left.13.0 / 14.9^{\circ} \mathrm{C}\right)$. Although this difference could be explained by the higher cationic charge of the trimer (6+ for the CTIversus $4+$ for the CBI), the poor activity of the trisphenazine $(2,8-$ TrisPZ) that is also hexacationic argues against a dominant electrostatic effect ( see also (d)). Thus the large difference between the two compounds is more likely attributable to the higher rigidity of the CTI as compared to that of the corresponding CBI. To support this hypothesis, molecular dynamic simulation in a water box has been performed with the two compounds: the results presented in Figure 5 show that $3,3^{\prime}$-BisBP has an extremely high degree of flexibility and adopts a largely open conformation whilst $3,3^{\prime}$-TrisBP is strongly conformationally restrained [29].

Altogether the results of this primary screen confirm that the association between the macrocycles and the quadruplex-DNA is strongly dependent on both the rigidity and the topology of the macrocyclic framework. Finally, as depicted in Figure 6, the behaviour of the majority of compounds shows a poor dependency on the cation present in the medium, thereby confirming that the quadruplexrecognition is primarily governed by tetrad-recognition.

\section{Selection of Highly Selective Ligands}

The first selection based on the amplitude of the F21T stabilisation induced by the ligand resulted in the selection of 16 compounds. For entering the second round of experiments, we further decided to arbitrary remove two candidates $\left(3,3^{\prime}\right.$-BisBP and 2,7-NP/9,10-AN), since they do not reach the affinity threshold $\left(\Delta T_{1 / 2}=10^{\circ} \mathrm{C}\right)$ in the two cationic conditions (Figure 4$)$. The 14 remaining compounds were thus subjected to the second selection step that consists in reproducing the melting experiment of F21T in the presence of the nonlabelled duplex-DNA competitor ds26. As shown in previous works, the presence of the duplex-DNA competitor diminishes the quadruplex-binding of nonselective compounds (thus resulting in decreased $\Delta T_{1 / 2}$ values) and poorly affects the binding of selective compounds (thus resulting in unchanged $\Delta T_{1 / 2}$ values). The competitive FRET-melting assay enables thus a rapid evaluation of quadruplex- over duplex-DNA selectivity, a criterion that is of utmost importance for further developments of quadruplex ligands in cell-based assays.

Competitive FRET-melting experiments were carried out in the conditions used in the first experiment [15], that is, with $0.2 \mu \mathrm{M}$ F21T, $1 \mu \mathrm{M}$ ligand without ds 26 or with two different concentrations of $\mathrm{ds} 26$ ( 3 and $10 \mu \mathrm{M}$, i.e., 15 - and 50-molar excess relative to $\mathrm{F} 21 \mathrm{~T}$ ). These experiments have been performed with the 14 selected macrocycles both in $\mathrm{Na}^{+}$ and $\mathrm{K}^{+}$conditions; the results ( $\Delta T_{1 / 2}$ values) are summarized as bar graphs shown in Figure 7.

In this second selection, 8 compounds (whose name is squared in red in Figure 7, see also Table 1) appear to keep on stabilizing efficiently the quadruplex-DNA $\left(\Delta T_{1 / 2}>\right.$ $10^{\circ} \mathrm{C}$, red dashed line in Figure $7(\mathrm{a})$, lower red dashed line in Figure $7(\mathrm{~b}))$ in presence of $10 \mu \mathrm{M}$ of duplex-DNA (i.e., 2,9-BisPN, 2,7-NP/2,7-A, BisNP-1PY, BisNP-2PY, BisNP1FC, BisNP-2FC, 2,7-TrisNP, and 3, 3' -TrisBP); on the other hand, 6 compounds (2,7-BisNP, 2,7-BisNP-N, 2,6-BisNP, 1,5/2,6-BisNP, 4,5-BisA and BisNP-1NH2) are found less selective since their $\Delta T_{1 / 2}$ value was reduced to $<10^{\circ} \mathrm{C}$ in presence of $10 \mu \mathrm{M}$ of ds 26 . 


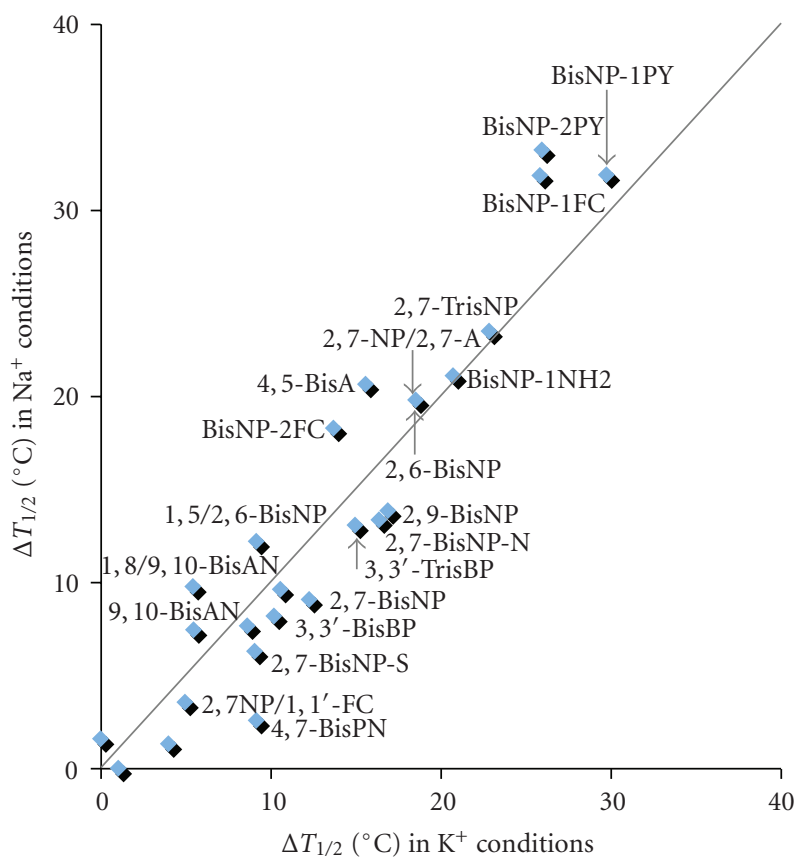

FIgURE 6: Plot of stabilization $\left(\Delta T_{1 / 2}\right)$ measured in $\mathrm{K}^{+}$- versus $\mathrm{Na}^{+}$-rich conditions for the CBI macrocycles.

To further examine the properties of the eight ligands selected after the second selection step, we quantified the quadruplex- versus duplex-DNA selectivity by the ${ }^{\text {FRET }} S$ value [30], which is defined as ${ }^{\mathrm{FRET}} S=\Delta T_{1 / 2}(10 \mu \mathrm{M}$ $\mathrm{ds} 26) / \Delta T_{1 / 2}$ (no ds26); consequently, ${ }^{\text {FRET }} S \rightarrow 1$ for highly selective ligands. This ratio has the advantage to paramter the $\Delta T_{1 / 2}$ value in presence of $\mathrm{ds} 26$ competitor as a function the $\Delta T_{1 / 2}$ value without ds26. Moderate (down to $0.36 / 0.48$, Table 1) to excellent ${ }^{\text {FRET }} S$ values (up to $1.01 / 0.98$, Table 1 ) were determined for the eight selected compounds. This values ranking enables us to discard the two ligands showing the lowest selectivity (i.e., ${ }^{\text {FRET }} S<0.5$ ), namely BisNP-2PY and 2,7-TrisNP, thereby leaving six promising candidates (2,9BisPN, 2,7-NP/2,7-A, BisNP-1PY, BisNP-1FC, and BisNP$2 \mathrm{FC}, 3,3^{\prime}$-TrisBP) for entering the final round of selection (vide infra).

It is worth mentioning here that the selectivity ranking is not globally affected by the nature of the cation $\left(\mathrm{Na}^{+}\right.$versus $\mathrm{K}^{+}$, Figures $7(\mathrm{a})$ and $7(\mathrm{~b})$, resp., Table 1); however, the values are significantly higher in presence of $\mathrm{K}^{+}$, thereby indicating a higher resistance of the ligands to the competition of the duplex-DNA in these conditions. For this reason and also for the sake of clarity, we used only results obtained in $\mathrm{K}^{+}$(Figure $7(\mathrm{~b})$ ) for rationalizing the data: a close examination of the results enables us to identify three structural parameters that influence the selectivity of the quadruplex-recognition by the macrocycles, namely, (a) the presence of pendant arms, (b) the existence of a specific three-dimensional conformation, and (c) the rigidity of the macrocyclic framework.

(a) The presence of pendant side-arm(s): this parameter contributes strongly to the quadruplex-selectivity, as demonstrated by the much higher $\Delta T_{1 / 2}$ values obtained in presence of $10 \mu \mathrm{M}$ ds 26 for the monobrachial and bibrachial compounds $\left(\Delta T_{1 / 2}=21.5\right.$, $17.2,12.6$ and $11.5^{\circ} \mathrm{C}$ for BisNP-1PY, BisNP-1FC, BisNP-2PY, and BisNP-2FC, resp.) as compared with their nonsubstituted analogue 2,6-BisNP $\left(\Delta T_{1 / 2}=\right.$ $\left.5.6^{\circ} \mathrm{C}\right)$. Remarkably, pendant side-arms terminated by a functional group (pyrene (PY) or ferrocene (FC)) lead to ligands that exhibit higher quadruplexaffinity and -selectivity than their amino-terminated counterpart (i.e., BisNP-1NH $\mathrm{NH}_{2}$, Figure 7 and Table 1; e.g., in presence of $10 \mu \mathrm{M}$ ds $26, \Delta T_{1 / 2}=29.7$ versus $20.7^{\circ} \mathrm{C}$ and ${ }^{\mathrm{FRET}} S=0.72$ versus 0.38 for BisNP$1 \mathrm{PY}$ and BisNP-1NH $\mathrm{N}_{2}$, resp.). This clearly indicates that these functional groups are responsible for additional interactions with quadruplex-DNA, eventually with loops and/or grooves, which may result in the multiple anchorage of the ligand in its binding site. Finally, the better performances of monobrachial compounds as compared to bibrachial ones, both in terms of affinity (in presence of $10 \mu \mathrm{M}$ ds26, $\Delta T_{1 / 2}=29.7 / 25.8^{\circ} \mathrm{C}$ for BisNP-1PY/BisNP-1FC versus $25.9 / 13.6^{\circ} \mathrm{C}$ for BisNP-2PY/BisNP-2FC) and selectivity ( ${ }^{\mathrm{FRET}} S=0.72 / 0.66$ for BisNP-1PY/BisNP1FC versus $0.48 / 0.84$ for BisNP-2PY/BisNP-2FC) suggest that one pendant side-arm is enough to create optimized interactions with the quadruplexDNA. The second pendant side-arm may impair the quadruplex-binding due to steric hindrance and also may participate to create nonspecific interactions since it increases the global charge of the molecule.

(b) The existence of a specific 3D conformation: in the naphthalene (NP) series, the replacement of an NP 


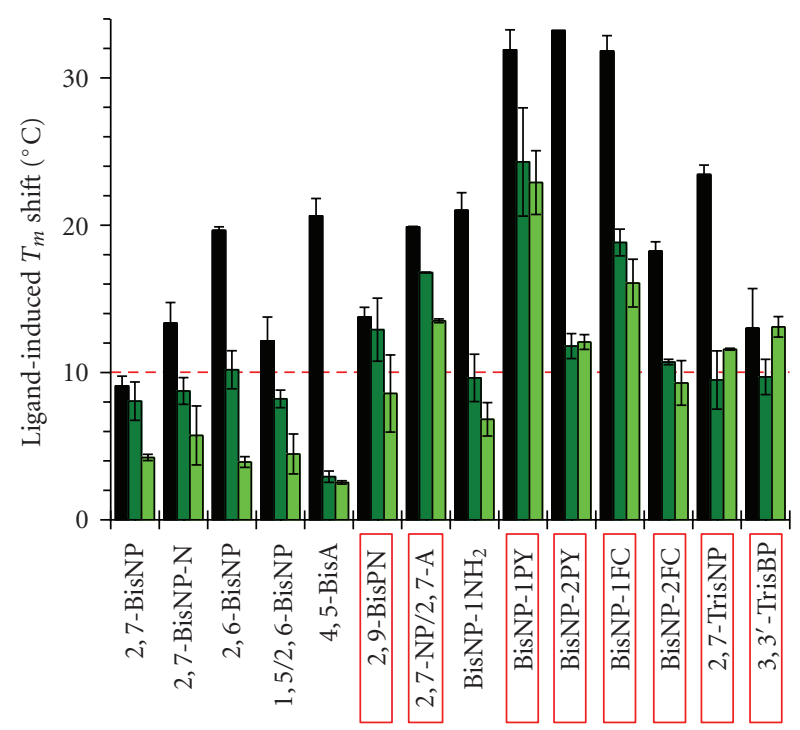

(a)
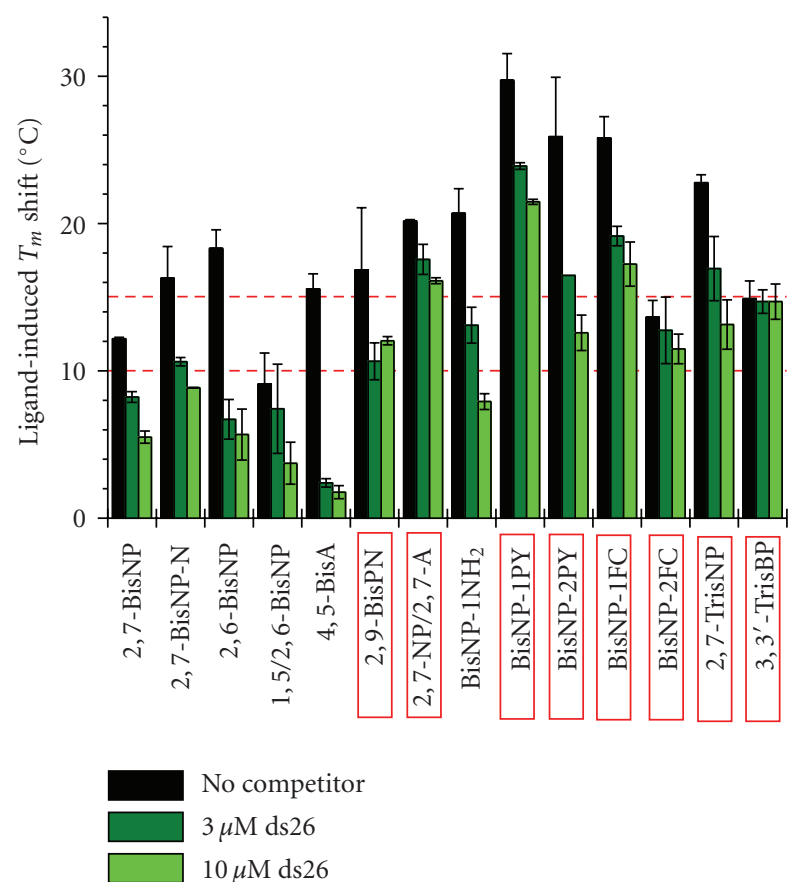

(b)

FIgure 7: Stabilisation of F21T oligonucleotide $\left(\Delta T_{1 / 2},{ }^{\circ} \mathrm{C}\right)$ induced by CBI and CTI macrocycles $(1 \mu \mathrm{M})$ in (a) $\mathrm{Na}^{+}-$and $(\mathrm{b}) \mathrm{K}^{+}$-rich conditions, for experiments carried out in the absence (black bars) or in the presence of 3 (dark green bars) or $10 \mu \mathrm{M}$ (light green bars) of the duplex competitor (ds26).

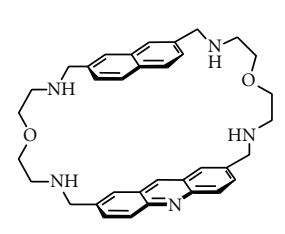

2,7-NP/2,7-A

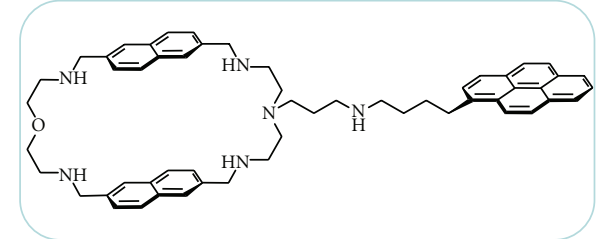

BisNP-1PY

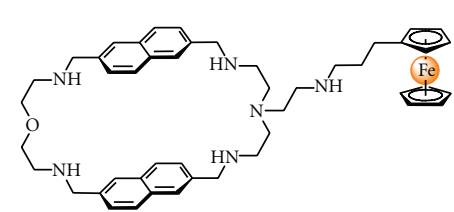

BisNP-1FC

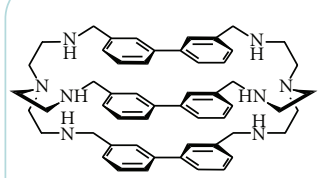

3,3'-TrisBP

FIGURE 8: Structures of the four most promising members of the macrocyclic series. 
TABLE 1: Competitive FRET-melting results of the 8 ligands selected after the second selection step.

\begin{tabular}{|c|c|c|c|c|c|c|c|c|}
\hline & \multicolumn{4}{|c|}{ in $\mathrm{Na}^{+}$-conditions } & \multicolumn{4}{|c|}{ in $\mathrm{K}^{+}$-conditions } \\
\hline & & $\Delta T_{1 / 2}\left({ }^{\circ} \mathrm{C}\right)$ & & ${ }^{\text {FRET }} S$ & & $\Delta T_{1 / 2}\left({ }^{\circ} \mathrm{C}\right)$ & & ${ }^{\text {FRET }} S$ \\
\hline & no competitior & $+3 \mu \mathrm{M}$ ds 26 & $+10 \mu \mathrm{M}$ ds 26 & $10 \mu \mathrm{M}$ ds 26 & no competitior & $+3 \mu \mathrm{M}$ ds 26 & $+10 \mu \mathrm{M}$ ds 26 & $10 \mu \mathrm{M} \mathrm{ds} 26$ \\
\hline 2,9-BisPN & 13.7 & 12.9 & 8.6 & 0.62 & 16.8 & 10.6 & 12.0 & 0.71 \\
\hline 2,7-NP/2,7-A & 19.9 & 16.8 & 13.5 & 0.68 & 20.1 & 17.6 & 16.1 & 0.79 \\
\hline BisNP-1PY & 31.9 & 24.3 & 22.9 & 0.71 & 29.7 & 23.9 & 21.5 & 0.72 \\
\hline BisNP-2PY & 33.2 & 11.8 & 12.0 & 0.36 & 25.9 & 16.5 & 12.6 & 0.48 \\
\hline BisNP-1FC & 31.8 & 18.8 & 16.1 & 0.50 & 25.8 & 19.1 & 17.2 & 0.66 \\
\hline BisNP-2FC & 18.2 & 10.7 & 9.3 & 0.51 & 13.6 & 12.7 & 11.5 & 0.84 \\
\hline 2,7-TrisNP & 23.4 & 9.5 & 11.6 & 0.49 & 22.8 & 16.9 & 13.1 & 0.57 \\
\hline $3,3^{\prime}$-TrisBP & 13.0 & 9.7 & 13.1 & 1.01 & 14.9 & 14.7 & 14.7 & 0.98 \\
\hline
\end{tabular}

unit in 2,7-BisNP by an acridine unit (i.e., 2,7$\mathrm{NP} / 2,7-\mathrm{A}$ ) increases the internal stacking interactions between the aromatic units, which in turn results in a more stable semi-closed conformation; given that 2,7-NP/2,7-A displays a better binding properties than 2,7-BisNP, both in terms of affinity (in presence of $10 \mu \mathrm{M}$ ds $26, \Delta T_{1 / 2}=20.1$ versus $12.2^{\circ} \mathrm{C}$ ) and selectivity ( ${ }^{\mathrm{FRET}} S=0.79$ versus 0.45 ), we can conclude that a particular topology could be highly favorable for increasing the efficiency of the ligand/quadruplex-DNA interactions. The same trend is observed when the NP units are replaced by the surface-extended phenanthroline (PN) units; the resulting compound, 2,9-BisPN, displays improved performances as compared to 2,7-BisNP (in presence of $10 \mu \mathrm{M} \mathrm{ds} 26, \Delta T_{1 / 2}=16.8^{\circ} \mathrm{C}$, and ${ }^{\mathrm{FRET}} S=0.71$ ). These two cases indicate that subtle modifications of the aromatic units that compose the CBI scaffold significantly increase the selectivity; these modifications may contribute to determine a particular topology of the CBI, thus disfavoring the association with duplexDNA. Interestingly, the crystal structure of 2,9-BisPN has recently described [31] evidence of a "horseshoe" conformation that may be prone to fit into the quadruplex-DNA bonding site. The importance of the 3D topology suggested here is in line with the role of the connectivity observed during the primary screen (vide supra).

(c) Finally, in the NP series, the formal introduction of a third NP branch in 2,7-BisNP scaffold significantly improves the binding properties of the resulting compounds (i.e., 2,7-TrisNP, in presence of $10 \mu \mathrm{M}$ ds26, $\Delta T_{1 / 2}=22.7$, and $\left.{ }^{\mathrm{FRET}} S=0.57\right)$; we can thus conclude that, given that 2,7-TrisNP is structurally more constrained than 2,7-BisNP, the rigidity of the ligand is a valuable parameter to control when searching to improve the quality of the recognition of the DNA target. The same trend is observed in the bipyridine (BP) series, since 3, $3^{\prime}$-TrisBP displays a higher quadruplex-affinity than $3,3^{\prime}$ - $\operatorname{BisBP}\left(\Delta T_{1 / 2}=\right.$ 14.9 versus $10.2^{\circ} \mathrm{C}$ ); interestingly, $3,3^{\prime}$-TrisBP shows a quite exceptional selectivity (with ${ }^{\mathrm{FRET}} S>0.98$ ), although its stabilizing effect is modest as compared to 2,7-TrisNP. These two examples demonstrate the interest of the CTI design for improving the quadruplex-selectivity, supporting the observation that the rigidity of the CBI is not only favorable for the quadruplex-binding but also for decreasing the duplex-binding. Last but not least, these results also indicate that electrostatic interactions are not critically determinant for the binding of CTI to both quadruplex- and duplex-DNA.

Thus, the two-step selection process described herein (step 1: affinity, step 2: selectivity) enables the rapid identification of six candidates (2,9-BisPN, 2,7-NP/2,7-A, BisNP1PY, BisNP-1FC, BisNP-2FC, and 3, 3'-TrisBP) with remarkable quadruplex-interacting properties, that is, high affinity and selectivity. To further increase the selection pressure and select hits for subsequent developments, we decided to focus our attention on compounds that display $\Delta T_{1 / 2} \geq$ $15^{\circ} \mathrm{C}$ in presence of $10 \mu \mathrm{M}$ ds 26 (upper red dashed line in Figure 7(b)). Four compounds fulfill this requirement, namely, 2,7-NP/2,7-A, BisNP-1PY, BisNP-1FC, and 3, $3^{\prime}-$ TrisBP (Figures 7 and 8 , it is worth noting that this selection has been extended to $3,3^{\prime}$-TrisBP, since its $\Delta T_{1 / 2}$ in presence of $10 \mu \mathrm{M} \mathrm{ds} 26\left(14.7^{\circ} \mathrm{C}\right)$ is an average value resulting from experiments with $\Delta T_{1 / 2} \geq 15^{\circ} \mathrm{C}$ ). Amongst these four compounds, two were thus elected as the most promising compounds over the 26 macrocycles screened: (i) BisNP$1 \mathrm{PY}$, since this CBI combines the best affinity and selectivity on the basis of the three values used for the selection procedure (in $\mathrm{K}^{+}$conditions: $\Delta T_{1 / 2}=29.7$ and $21.5^{\circ} \mathrm{C}$ in absence and presence of $10 \mu \mathrm{M}$ ds 26 , resp. ${ }^{\text {RRET }} S=0.72$; in $\mathrm{Na}^{+}$conditions: $\Delta T_{1 / 2}=31.9$ and $22.9^{\circ} \mathrm{C}$ in absence and presence of $10 \mu \mathrm{M}$ ds 26 , resp., ${ }^{\text {FRET }} S=0.71$ ), and (ii)- 3, $3^{\prime}$ TrisBP, since, while displaying a decent affinity, this CTI reaches an unprecedented level of quadruplex- over duplexDNA selectivity $\left({ }^{\text {FRET }} S=1.01\right.$ and 0.98 in $\mathrm{Na}^{+}$and $\mathrm{K}^{+}$ conditions, resp.).

\section{Conclusion}

The CBIs were initially designed to trap flat aromatic substrates between their aromatic units [22, 26, 32]; however, it turned out very rapidly that these compounds 
display remarkable binding preference for single-stranded and locally unpaired DNA (abasic [33], mismatched sites) $[17,18,21,34]$ and various secondary structures (hairpins [35], trinucleotide repeats [36], G-quadruplex) [9-11, 37]. We show here that this class of macrocycles offers unique advantages for targeting G-quadruplex-DNA.

The two-step selection procedure followed herein as well as the structural diversity of the collection studied enabled us to identify several structural features that govern the efficiency of the quadruplex-recognition by the CBI ligands. Among these, the presence of a pendant side-arm and the existence of a particular topological arrangement appear to be strong determinants. The selected hits possess sophisticated architectures and are thus likely to create multiple contacts with the quadruplex-DNA structure. This should result from a complex interplay of $\pi$-stacking interactions, $\mathrm{H}$-bonding, and electrostatic forces both with the accessible G-tetrad of the quadruplex-DNA and with the quadruplexelements that surround the G-tetrad (loops and/or grooves). These secondary interactions may be at the origin of the high selectivity observed.

In conclusion, we have performed the first step toward the identification of two molecules that are highly promising ligands of the human telomeric quadruplex in vitro and opened the way towards new molecular designs of high efficiency. We are thus now performing further studies with these ligands to investigate their peculiar binding mode and in vivo properties.

\section{Acknowledgments}

The authors would like to thank sincerely their coworkers, C. Guetta, A. De Cian, E. Largy, and L. Lacroix, for technical assistance and stimulating scientific discussions related to Gquadruplex DNA and ligands. A special acknowledgment is due to J. R. R. Tolkien for the title inspiration.

\section{References}

[1] D. Monchaud and M.-P. Teulade-Fichou, "A hitchhiker's guide to G-quadruplex ligands," Organic and Biomolecular Chemistry, vol. 6, no. 4, pp. 627-636, 2008.

[2] A. Arola and R. Vilar, "Stabilisation of G-quadruplex DNA by small molecules," Current Topics in Medicinal Chemistry, vol. 8, no. 15, pp. 1405-1415, 2008.

[3] M. Franceschin, "G-quadruplex DNA structures and organic chemistry: more than one connection," European Journal of Organic Chemistry, no. 14, pp. 2225-2238, 2009.

[4] S. Neidle, "The structures of quadruplex nucleic acids and their drug complexes," Current Opinion in Structural Biology, vol. 19, no. 3, pp. 239-250, 2009.

[5] K. Shin-ya, K. Wierzba, K. Matsuo, et al., "Telomestatin, a novel telomerase inhibitor from Streptomyces anulatus," Journal of the American Chemical Society, vol. 123, no. 6, pp. 1262-1263, 2001.

[6] F. X. Han, R. T. Wheelhouse, and L. H. Hurley, "Interactions of TMPyP4 and TMPyP2 with quadruplex DNA. Structural basis for the differential effects on telomerase inhibition," Journal of the American Chemical Society, vol. 121, no. 15, pp. 3561-3570, 1999.
[7] E. Izbicka, R. T. Wheelhouse, E. Raymond, et al., "Effects of cationic porphyrins as G-quadruplex interactive agents in human tumor cells," Cancer Research, vol. 59, no. 3, pp. 639644, 1999.

[8] D.-F. Shi, R. T. Wheelhouse, D. Sun, and L. H. Hurley, "Quadruplex-interactive agents as telomerase inhibitors: synthesis of porphyrins and structure-activity relationship for the inhibition of telomerase," Journal of Medicinal Chemistry, vol. 44, no. 26, pp. 4509-4523, 2001.

[9] M.-P. Teulade-Fichou, C. Carrasco, L. Guittat, et al., "Selective recognition of G-quadruplex telomeric DNA by a bis(quinacridine) macrocycle," Journal of the American Chemical Society, vol. 125, no. 16, pp. 4732-4740, 2003.

[10] C. Allain, D. Monchaud, and M.-P. Teulade-Fichou, "FRET templated by G-quadruplex DNA: a specific ternary interaction using an original pair of donor/acceptor partners," Journal of the American Chemical Society, vol. 128, no. 36, pp. 11890-11893, 2006.

[11] V. Gabelica, E. S. Baker, M.-P. Teulade-Fichou, E. De Pauw, and M. T. Bowers, "Stabilization and structure of telomeric and c-myc region intramolecular G-quadruplexes: the role of central cations and small planar ligands," Journal of the American Chemical Society, vol. 129, no. 4, pp. 895-904, 2007.

[12] J.-L. Mergny, L. Lacroix, M.-P. Teulade-Fichou, et al., "Telomerase inhibitors based on quadruplex ligands selected by a fluorescence assay," Proceedings of the National Academy of Sciences of the United States of America, vol. 98, no. 6, pp. 30623067, 2001.

[13] C. Hounsou, L. Guittat, D. Monchaud, et al., "G-quadruplex recognition by quinacridines: a SAR, NMR, and biological study," ChemMedChem, vol. 2, no. 5, pp. 655-666, 2007.

[14] D. Monchaud, C. Allain, H. Bertrand, et al., "Ligands playing musical chairs with G-quadruplex DNA: a rapid and simple displacement assay for identifying selective G-quadruplex binders," Biochimie, vol. 90, no. 8, pp. 1207-1223, 2008.

[15] A. De Cian, L. Guittat, M. Kaiser, et al., "Fluorescence-based melting assays for studying quadruplex ligands," Methods, vol. 42, no. 2, pp. 183-195, 2007.

[16] A. De Cian, L. Guittat, K. Shin-ya, J. F. Riou, and J. L. Mergny, "Affinity and selectivity of G4 ligands measured by FRET," Nucleic Acids Symposium Series, no. 49, pp. 235-236, 2005.

[17] M. Bahr, V. Gabelica, A. Granzhan, M.-P. Teulade-Fichou, and E. Weinhold, "Selective recognition of pyrimidine-pyrimidine DNA mismatches by distance-constrained macrocyclic bisintercalators," Nucleic Acids Research, vol. 36, no. 15, pp. 50005012, 2008.

[18] A. Granzhan, E. Largy, N. Saettel, and M.-P. TeuladeFichou, "Macrocyclic DNA-mismatch-binding ligands: structural determinants of selectivity," Chemistry-A European Journal, vol. 16, no. 3, pp. 878-889, 2010.

[19] D. M. Crothers, "Calculation of binding isotherms for heterogenous polymers," Biopolymers, vol. 6, no. 4, pp. 575-584, 1968.

[20] J. D. McGhee and P. H. Von Hippel, "Theoretical aspects of DNA protein interactions: cooperative and non cooperative binding of large ligands to a one dimensional homogeneous lattice," Journal of Molecular Biology, vol. 86, no. 2, pp. 469489, 1974.

[21] A. Granzhan and M.-P. Teulade-Fichou, "A fluorescent bisanthracene macrocycle discriminates between matched and mismatch-containing DNA," Chemistry-A European Journal, vol. 15, no. 6, pp. 1314-1318, 2009.

[22] A. Granzhan and M.-P. Teulade-Fichou, "Synthesis of monoand bibrachial naphthalene-based macrocycles with pyrene or 
ferrocene units for anion detection," Tetrahedron, vol. 65, no. 7, pp. 1349-1360, 2009.

[23] S. Burge, G. N. Parkinson, P. Hazel, A. K. Todd, and S. Neidle, "Quadruplex DNA: sequence, topology and structure," Nucleic Acids Research, vol. 34, no. 19, pp. 5402-5415, 2006.

[24] D. J. Patel, A. T. Phan, and V. Kuryavyi, "Human telomere, oncogenic promoter and 5'-UTR G-quadruplexes: diverse higher order DNA and RNA targets for cancer therapeutics," Nucleic Acids Research, vol. 35, no. 22, pp. 7429-7455, 2007.

[25] J. Dai, M. Carver, and D. Yang, "Polymorphism of human telomeric quadruplex structures," Biochimie, vol. 90, no. 8, pp. 1172-1183, 2008.

[26] M. Dhaenens, J.-M. Lehn, and J.-P. Vigneron, "Molecular recognition of nucleosides, nucleotides and anionic planar substrates by a water-soluble bis-intercaland-type receptor molecule," Journal of the Chemical Society, Perkin Transactions 2, no. 7, pp. 1379-1381, 1993.

[27] M. P. Teulade-Fichou, J.-P. Vigneron, and J.-M. Lehn, "Molecular recognition of nucleosides and nucleotides by a watersoluble cyclo-bis-intercaland receptor based on acridine subunits," Journal of Supramolecular Chemistry, vol. 5, no. 2, pp. 139-147, 1995.

[28] M.-P. Teulade-Fichou, J.-P. Vigneron, and J.-M. Lehn, "Detection of organic anions in water through complexation enhanced fluorescence of a macrobicyclic tris-acridine cryptand," Journal of the Chemical Society. Perkin Transactions 2, vol. 10, pp. 2169-2175, 1996.

[29] E. F. Pettersen, T. D. Goddard, C. C. Huang, et al., "UCSF Chimera- a visualization system for exploratory research and analysis," Journal of Computational Chemistry, vol. 25, no. 13, pp. 1605-1612, 2004.

[30] A. De Cian, P. Grellier, E. Mouray, et al., "Plasmodium telomeric sequences: structure, stability and quadruplex targeting by small compounds," ChemBioChem, vol. 9, no. 16, pp. 27302739, 2008.

[31] C. Cruz, R. Delgado, M. G. B. Drew, and V. Félix, "Evaluation of the binding ability of a novel dioxatetraazamacrocyclic receptor that contains two phenanthroline units: selective uptake of carboxylate anions," Journal of Organic Chemistry, vol. 72, no. 11, pp. 4023-4034, 2007.

[32] O. Baudoin, F. Gonnet, M.-P. Teulade-Fichou, J.-P. Vigneron, J.-C. Tabet, and J.-M. Lehn, "Molecular recognition of nucleotide pairs by a cyclo-bis-intercaland-type receptor molecule: a spectrophotometric and electrospray mass spectrometry study," Chemistry - A European Journal, vol. 5, no. 9, pp. 2762-2771, 1999.

[33] M. Jourdan, J. Garcia, J. Lhomme, M.-P. Teulade-Fichou, J.-P. Vigneron, and J.-M. Lehn, "Threading bis-intercalation of a macrocyclic bisacridine at abasic sites in DNA: nuclear magnetic resonance and molecular modeling study," Biochemistry, vol. 38, no. 43, pp. 14205-14213, 1999.

[34] A. David, N. Bleimling, C. Beuck, J.-M. Lehn, E. Weinhold, and M.-P. Teulade-Fichou, "DNA mismatch-specific base flipping by a bisacridine macrocycle," ChemBioChem, vol. 4, no. 12, pp. 1326-1331, 2003.

[35] A. Slama-Schwok, F. Peronnet, E. Hantz-Brachet, et al., "A macrocyclic bis-acridine shifts the equilibrium from duplexes towards DNA hairpins," Nucleic Acids Research, vol. 25, no. 13, pp. 2574-2581, 1997.

[36] S. Amrane, A. De Cian, F. Rosu, et al., "Identification of trinucleotide repeat ligands with a FRET melting assay," ChemBioChem, vol. 9, no. 8, pp. 1229-1234, 2008.
[37] P. Alberti, J. Ren, M.-P. Teulade-Fichou, et al., "Interaction of an acridine dimer with DNA quadruplex structures," Journal of Biomolecular Structure and Dynamics, vol. 19, no. 3, pp. 505-513, 2001. 

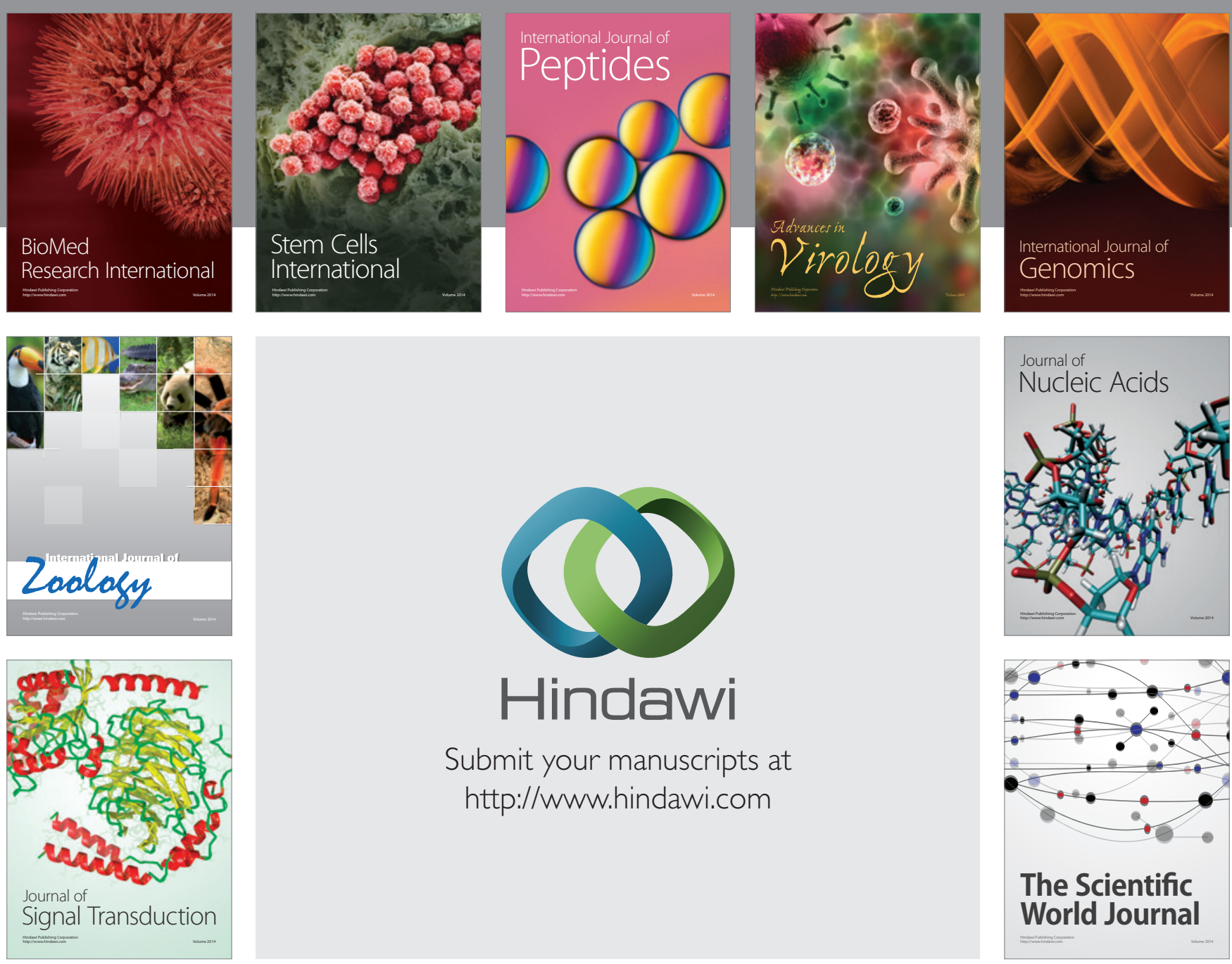

Submit your manuscripts at

http://www.hindawi.com
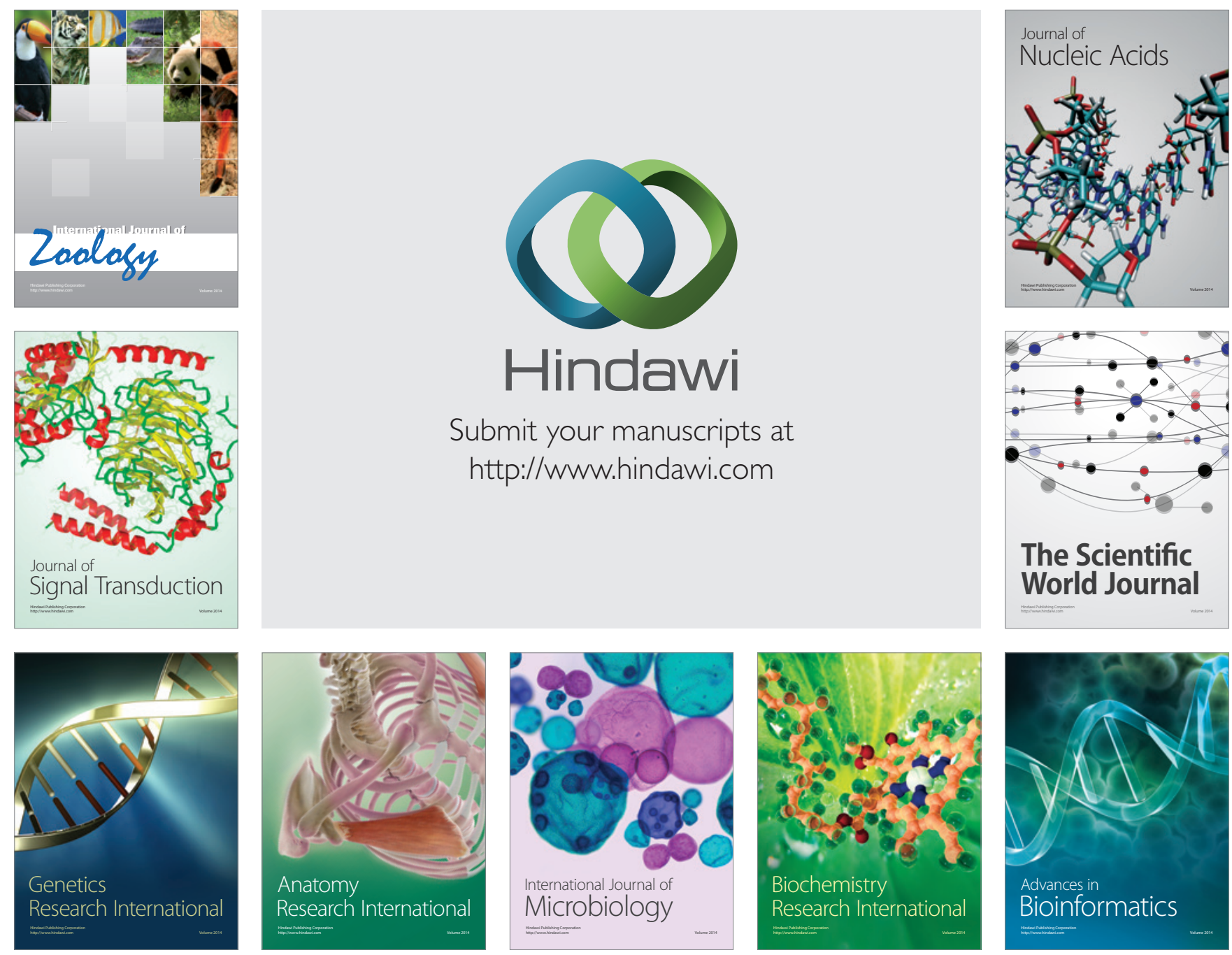

The Scientific World Journal
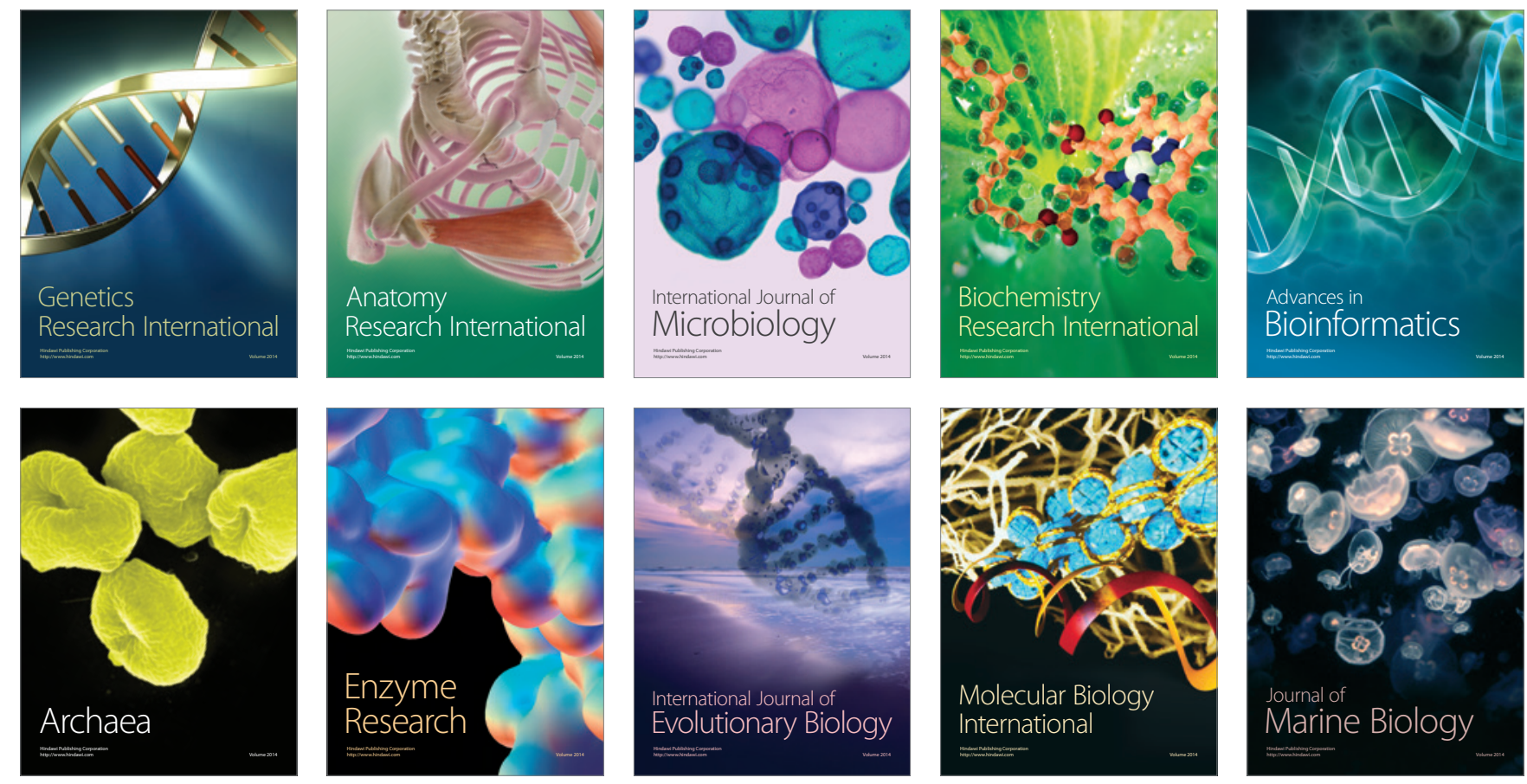